\title{
A educação formal nas obras de Hannah Arendt e Carl. G. Jung: possíveis diálogos com a modernidade $^{1}$
}

\author{
Renata Fernandez Targino*
}

\begin{abstract}
Resumo
O artigo busca, por meio de um levantamento teórico sobre as concepções de educação formal presentes na obra da filósofa Hannah Arendt e o do Psiquiatra Carl G. Jung, pai da Psicologia Analítica, refletir sobre os objetivos da Escola para tais autores e estabelecer algumas relações com jargões educacionais presentes atualmente tais como educar para mudar o mundo ou educar para o desenvolvimento de competências. Acredita-se que a Escola em nossa época acabou por deturpar seu compromisso em apresentar o mundo às novas gerações, além de ter lançado ao esquecimento sua importância social e psíquica em levar a criança do ambiente familiar para mundo público.
\end{abstract}

Palavra chave: Educação Formal; Psicologia Analítica; Hannah Arendt.

\section{The Formal Education in Hannah Arendt and Carl. G. Jung: Possible dialogues with modernity}

\begin{abstract}
This article aims to discuss the concepts of formal education in the philosopher Hannah Arendt and the psychiatrist Carl G. Jung's works. Beyond this discussion, this paper has the purpose of establishing some connections between these authors and bringing a critical view to some wellknown sentences in the educational area such as the importance of educating to change the world or the development of skills through education. That School in our days is believed to have lost its commitment to the introduction of the new generations into the world as well as to have forgotten the social and psychical importance at leading the children from the family atmosphere.

Keywords: Formal Education; Analitycal Psychology; Hannah Arendt.
\end{abstract}

A Escola talvez seja uma das instituições mais presentes em nossas memórias de infância, deixando marcas profundas em cada um de nós. Todos nós temos histórias - que nos emocionam, nos alegram e nos entristecem - do período que passamos dentro de seus muros. No Brasil, o ensino formal obrigatório é estabelecido pela Lei de Diretrizes Básicas $\mathrm{n}^{\circ}$ 9.394, de 20 de dezembro de 1996, a partir dos seis anos de idade até a conclusão do Ensino Fundamental de nove anos, tornando-se optativo no Ensino Médio, embora o Estado ainda tenha a obrigatoriedade em oferecê-lo. Mas uma questão emerge dessa constatação: qual é a função da instituição escolar? Pela lei federal, sua finalidade é o desenvolvimento pleno do educando, seu preparo para o exercício da cidadania e sua qualificação para o trabalho. Se por um lado é possível identificar nessa afirmação um ideal de que a escola tenha papel fundamental na formação global do homem e um vínculo com a formação do cidadão, por outro, um olhar mais atento nos mostra o quanto tais afirmações são vagas, deixando em aberto questões fundamentais como o que seria esse desenvolvimento pleno ou o que deveríamos entender por preparação para cidadania.
Tais questões podem ser respondidas por meio de um estudo das colocações da filósofa Hannah Arendt sobre o tema. Neste artigo, além de nos aprofundarmos em seu pensamento, também lançaremos nosso olhar para os escritos de C.G. Jung sobre a temática da educação formal de crianças e jovens, para que possamos tecer aproximações entre esses dois autores e reflexões sobre a Educação nos dias atuais.

Primeiramente, ambos os autores não foram educadores profissionais e nem tiveram a intenção de vir a sê-lo, tampouco buscaram desenvolver projetos políticos pedagógicos, mas sim, foram pessoas que se dispuseram a pensar a educação e a Escola em seu tempo, com um olhar crítico com base em seus referenciais teóricos. Talvez seja por isso que esses dois autores, mesmo tendo escrito pouco a respeito da educação e do papel da escola, trazem contribuições tão pertinentes para a temática, já que possuem um olhar distanciado e questionador das práticas vigentes.

Hannah Arendt (1906-1975), judia e alemã, formou-se em Filosofia, tendo sido aluna de Heidegger e Jaspers, além de ser contemporânea de grandes nomes da escola Frankfurtiana, tais como

\footnotetext{
* Endereço eletrônico: renataftargino @ gmail.com
} 
Adorno e Walter Benjamin. Foi inclusive a ela que Benjamin confiara seus escritos inéditos um pouco antes de seu suicídio, para que os entregassem a Adorno, nos Estados Unidos. Viveu como apátrida entre os anos de 1933 e 1951, quando conseguiu a cidadania americana. Embora tenha convivido com tais expoentes, desenvolveu um pensamento próprio, buscando compreender a crise da modernidade, a ascensão dos regimes totalitários e o desaparecimento da esfera pública, visto como o único lugar em que é possível a construção de significados partilhados.

Carl G. Jung (1875-1961), suíço, formou-se em Psiquiatria, tendo iniciado sua carreira com Bleuler, famoso psiquiatra do início do século XX. Desenvolveu estudos sobre esquizofrenia e associação verbal, através dos quais formulou o conceito de complexo afetivo, termo que viria ser um dos mais importantes tanto para sua teoria como para a Psicanálise. Entre os anos de 1907 e 1912, manteve intensa relação com Freud, momento em que ambos estavam iniciando a formulação de suas abordagens teóricas; porém, após a publicação da obra Metamorfose e Símbolos da Libido, Freud rompe suas relações com o autor, tecendo duras críticas ao livro e ao próprio Jung. A partir de então, ambos seguem por caminhos distintos e Jung desenvolve sua abordagem, a Psicologia Analítica.

\section{A educação em Arendt}

O pensamento de Arendt sempre teve destaque dentro das ciências políticas, mas apenas nos últimos anos suas ideias começaram gradativamente a ganhar evidência também na área educacional. A autora escreveu um único ensaio sobre a educação formal, sob o título "A crise na educação", publicado em 1958. A percepção de uma crise nessa área permitiu que a filósofa realizasse uma reflexão sobre esse tema, já que para a autora a própria crise se constitui como um momento em que há a dissolução das significações comuns, o que torna possível repensar o momento histórico vivido. Arendt coloca que, embora a crise na educação possa se expressar de uma forma singular em diferentes regiões, ela seria apenas mais uma faceta da crise da modernidade. Antes de nos aprofundarmos na temática da educação formal, é interessante esclarecer ao leitor alguns conceitos fundamentais da obra dessa autora para a compreensão do desenvolvimento de suas ideias.

A autora distingue as atividades humanas em três categorias: labor, trabalho e ação. O labor seria a atividade que visa à manutenção e perpetuação da vida no que tange aos aspectos orgânicos, tanto do indivíduo, quanto da espécie; assim, essa atividade se insere no clico vital e seu produto acaba sendo consumido dentro deste mesmo ciclo. Já no trabalho ocorreria um rompimento com o ciclo vital, pois ele gera uma produção material e simbólica, o que lhe dá durabilidade e permanência no mundo (ARENDT, 2003). É interessante notar que essa durabilidade não está diretamente ligada ao produto material do trabalho, não é algo intrínseco do objeto, mas sim, surge nas relações de sentido que os homens estabelecem com esses artífices produzidos. Por exemplo, se nunca mais ninguém abrir um determinado livro, ou manuseá-lo com o cuidado que esse tipo de objeto demanda, se ele for deixado a sua própria sorte, abandonado pelos homens, o livro passa a ser apenas um amontoado de papel, irá se decompor e novamente integrará o ciclo vital, retornando para a natureza. Portanto, faz-se necessário que o objeto material dure juntamente com seu significado, para haver, assim, uma permanência no mundo.

Se no trabalho há uma criação material que lhe dá durabilidade, a ação não tem essa mediação, só existindo no momento em que ocorre, como fim em si mesmo. No pensamento de Arendt (2003), é na ação que um indivíduo se mostra para o mundo, por meio de seus atos e palavras, liberto das necessidades vitais e à luz pública, constituindo assim a atividade humana por excelência, uma atividade feita por homens, entre homens e para outros homens. É paradoxal que, embora só exista no momento em que ocorre, ela é a única das atividades capaz de constituir memória, dando aos homens imortalidade, já que, por meio da ação, ou seja, seus feitos e palavras, um indivíduo também acaba ganhando permanência no mundo todas as vezes que sua história singular for resgatada e recontada.

Com base nesses pressupostos, Arendt diferencia natureza de mundo. A primeira é caracterizada pelo labor, pelas atividades intrínsecas de manutenção da vida orgânica e, consequentemente, não é exclusiva à espécie humana. Já o segundo é caracterizado pelo trabalho e ação, sendo assim eminentemente humano.

A autora também distingue de forma relevante em sua obra a esfera privada e a esfera pública. A primeira é marcada pela proteção da luz pública, por tudo aquilo que deve ser cuidado, já que, caso isso não ocorresse, o público acabaria o 
deteriorando; é a esfera da intimidade, da família, do nascimento, da morte e da reprodução. Já a segunda constitui-se das ações, de tudo aquilo sobre o que a luz deve incidir para ter seu sentido pleno; é o campo da política por excelência, não a partidária, mas a marcada pela persuasão e circulação da palavra, e da constituição de um espaço comum e de significações compartilhadas.

Porém, desde o século XVIII, no interior dos processos próprios à modernidade, emerge uma terceira esfera: a social, que abrange, simultaneamente, os espaços e as funções que eram próprias do ambiente privado e do público, o que acaba por degradar ambos. A dissolução da esfera pública, compreendida como o espaço no qual a palavra pode circular e as pessoas podem agir de fato, tem por consequência que as pessoas cada vez mais apenas comportam-se e não agem, submetendo-se às regras de uma burocracia, um governo de ninguém regido pela mais restrita relação meio-fins, perdendo também a capacidade de pensar, resultando no que Arendt chamou de a banalidade do mal (ARENDT, 1999). Os homens deixam de se responsabilizar por suas ações no mundo, e a falta de uma perspectiva de permanência acaba por tornar a vida efêmera, ameaçando o próprio mundo.

A partir desses pressupostos, a educação e a Escola, para Arendt (2009), tem a função de preservar o novo - crianças e jovens, aqueles que ainda não estão com suas personalidades suficientemente formadas - dos assédios e perigos tanto do mundo quanto da natureza, para que possam se desenvolver, adquirir condições de fruir no mundo ao final do processo educacional e vir a agir de fato, e não apenas se comportarem. Embora a educação busque proteger os recém-chegados no mundo, crianças e jovens, deve-se esclarecer que, para a autora, esse não é um fim em si mesmo. A educação, e nesse momento Arendt está se referindo à educação formal, tem um compromisso com o mundo mediante sua apresentação progressiva aos recém-chegados e com a inserção gradual das novas gerações. Assim, temos que a passagem da esfera privada para esfera pública se dá por meio da Escola.

Além disso, a educação também tem a tarefa de buscar realizar a conservação do mundo enquanto nele realiza a inserção gradual da criança, mediante a transmissão dos conteúdos mais caros e belos produzidos pela humanidade, para que eles não se percam e sejam dissolvidos pelo tempo. Assim, o processo educacional e o professor acabam se tornando os principais responsáveis pela transmissão dos bens culturais, a herança das próximas gerações.

É interessante observar que, ao mesmo tempo em que a Escola, para essa autora, tem uma característica de preservação do mundo, ela também é a grande responsável pela sua renovação. Embora de forma indireta, a escola também acaba tendo esse caráter assegurado, tanto pelo fato de preservar a criança dos assédios da esfera pública e da natureza, garantindo que ela venha a se desenvolver, como por introduzi-la no mundo compartilhado, no solo comum das tradições. A Escola apresenta à criança sua herança cultural e possibilita que ela venha, algum dia, a empreender algo novo, com a sua inserção no mundo, ou seja, com a inserção de alguém que nunca esteve por aqui antes, revelando sua singularidade, podendo tomar partido na esfera pública e exercendo a política. A Escola constitui, nesse sentido, uma preparação para a cidadania.

Porém, como já dito anteriormente, com o avanço da esfera social, tanto a esfera privada como pública estão se degradando, e assim a educação para muitos acabou tendo seu sentido deturpado, tornando-se apenas mais um produto de consumo dentre outros em uma prateleira de supermercado. Nesse contexto, o próprio mundo transformou-se em um produto para ser consumido, jamais destinado a ser apropriado, e sua permanência passou a ser ameaçada.

\section{A educação em Jung}

Levando em conta a extensão de sua obra, Jung pouco escreveu sobre educação, ficando sua reflexão acerca dessa temática restrita a algumas conferências proferidas entre os anos de 1923 e 1942, além de alguns breves trechos ao longo das Obras Compiladas. Em nenhum momento o autor se propõe a construir um projeto pedagógico, mas sim a pensar a questão educacional sob o ponto de vista de sua teoria psicológica e tecer fios que auxiliariam pais, educadores e professores em sua prática.

Em sua conferência "A importância do inconsciente para a educação individual”, Jung (1928/2011a) distingue três tipos de educação. Embora não especifique que esteja falando principalmente da educação de crianças e jovens, sua conferência nos leva a crer que, nesse momento, o autor tenha tal enfoque. Dentre essas três modalidades propostas temos: a educação pelo exemplo, educação coletiva consciente e a educação individual. A educação pelo exemplo consiste 
naquela que ocorre de forma espontânea e inconsciente, como que por contágio, resultado, no caso da criança, da participação mística que estabelece com a psique de seus pais nos primeiros anos de vida. É a primeira forma de educação a que somos submetidos e nos acompanha ao longo da vida. Como coloca Furlanetto (2009), ao dissertar sobre a formação dos professores, essa capacidade de aprender de maneira inconsciente nunca se desfaz, apenas ganha características distintas conforme o indivíduo se desenvolve, cresce e produz consciência. A educação pelo exemplo talvez seja a mais eficaz de todas: na medida em que esse tipo de educação "se fundamenta em uma das propriedades primitivas da psique, será este método sempre eficiente, mesmo quando todos os outros métodos diretos falharem" (JUNG, 1928/2011a, p. 161).

É interessante esclarecer ao leitor o termo "participação mística", cunhado pelo pensador francês Lévy-Bruhl (1857-1939) e adotado por Jung ao longo de sua obra. Trata-se de um estado marcado pela indiferenciação original entre sujeito e objeto, em que não há limitações claras entre o eu e o outro na consciência: "o que acontece fora, acontece também dentro dele, e o que acontece dentro dele, acontece também fora." (JUNG, $1927 / 1984$, p. 159). É um fenômeno em que ocorre uma espécie de fusão psíquica entre os indivíduos, característico do estado mental da primeira infância, mas também presente de forma inconsciente no homem adulto, perceptível, por exemplo, em momentos em que ocorrem fenômenos de massas, quando uma espécie de identidade inconsciente coletiva é estabelecida entre os membros da multidão (JUNG, 1940/2011b).

Já a educação coletiva consciente é, para Jung (1928/2011a), aquela pautada por normas, princípios, conteúdos e métodos coletivos. Mesmo que não se dê em grupo, este tipo de educação é regido por determinadas características, que devem ser válidas e aplicáveis ao menos a uma dada quantidade de indivíduos. $O$ autor assume uma postura ambígua em relação à educação coletiva consciente, por vezes alertando quanto ao perigo da uniformização derivada desse tipo de educação, que, dependendo da força do que o autor chama de "índole individual", pode gerar uma total supressão da singularidade em favor das normas coletivas, resultando em indivíduos completamente adaptados à sociedade, mas inseguros em todas as situações em que for necessária uma decisão individual, cedendo à pressão coercitiva do grupo.
Ao mesmo tempo em que Jung (1928/2011a) alerta para tal perigo, ele também enfatiza a importância desse tipo de educação e coloca que para a maioria dos indivíduos ela é suficiente:

A educação coletiva é indispensável e não pode ser substituída por nenhuma outra coisa. Vivemos na coletividade humana $e$ precisamos de normas coletivas, do mesmo modo que devemos ter uma linguagem comum. Jamais devemos renunciar ao principio da educação coletiva para favorecer o desenvolvimento da índole individual, por mais que desejemos que certas qualidades preciosas do indivíduo não sejam sufocadas pela educação coletiva. Precisamos ponderar que uma qualidade individual não representa algo valioso em sentido absoluto, nem mesmo para o próprio indivíduo (JUNG, 1928/2011a, p. 163).

Jung (1928/2011a) contrapõe a educação coletiva consciente à educação individual, colocando que a educação individual deve ser aplicada para todos aqueles que apresentarem uma resistência insuperável à coletiva. Para o autor, o objetivo dessa modalidade de educação é o desenvolvimento da "índole específica do indivíduo" (JUNG, 1928/2011a, p. 163) que não conseguiu se adaptar a educação coletiva. Nesta modalidade todas as regras, normas, conteúdos e métodos coletivos devem ser tomados como segundo plano em favor do desenvolvimento singular do indivíduo.

Herbert Read ${ }^{2}$ (1982 apud SAIANI, 2003), tal como Jung (1928/2011a), também considera que a educação individual e coletiva são opostas e, em sua visão, até irreconciliáveis, do que Saviani (2003) discorda. Para este último, ao refletir sobre como os professores devem se posicionar frente a tais modalidades de educação, essas duas formas podem agir de maneira complementar, "já que é impossível a quem quer que seja 'chegar àquilo que é' sem levar em conta toda a tradição cultural da humanidade, ainda que seja para romper com paradigmas estabelecidos" (SAIANI, 2003, p. 17).

Concordamos com Saviani (2003), ao considerar essas duas modalidades de educação como complementares, podendo e devendo atuar de forma conjunta e articulada. Todos, não apenas as crianças, que têm resistência à educação coletiva 
podem se beneficiar de uma educação em que suas particularidades, histórias de vida, dificuldades, interesses, são levados em consideração no planejamento, em que haja um olhar do professor para o desenvolvimento individual do aluno, mesmo que seja em uma educação coletiva. Por outro lado, o indivíduo que não é inserido nas tradições culturais e normas coletivas acaba sendo relegado a sua própria sorte, deixado ao ostracismo. Ele não consegue fruir no mundo que é anterior a sua própria existência, mesmo que seja para posteriormente discordar do estabelecido e propor algo novo.

Apesar de Jung colocar a educação coletiva como fundamental, por várias vezes expressa seu receio quanto à uniformização que ela pode vir a acarretar, como corromper o que o indivíduo traz de mais próprio e em casos extremos formar "cidadãos idealmente obedientes para serem manejados como robôs por ditadores" (SILVEIRA, 1981, p.175), provavelmente como consequência de sua visão negativa a respeito dos próprios grupos humanos. Esse autor traz a questão dos grupos fortemente associada aos fenômenos de massa, alertando para os perigos de "regressão, contágio ou intoxicação psíquica, criação de dependência mútua, perda de autonomia, massificação e fuga do confronto consigo próprio" (FREITAS, 2005, p. 51) que o grupo pode desenvolver em seus membros.

Quando consideramos o contexto em que Jung escreveu grande parte de sua obra, que data da primeira metade do século XX, tendo presenciado as mazelas das duas Grandes Guerras Mundiais, a ascensão de regimes totalitários nazi-fascistas eleitos pelo povo e o extermínio de sete milhões de judeus, é compreensível sua postura. Freitas (2005), em concordância com Neumann (1995), discorda dessa posição, argumentando que a teoria junguiana carrega de forma intrínseca a articulação do individual e coletivo e inclusive, a autora propõe grupos vivenciais como forma de trabalho terapêutico dentro da abordagem da Psicologia Analítica.

Amnéris Maroni, em Jung: o poeta da Alma (1998), explicita a influência da obra de Nietzsche na construção do pensando de Jung, ao mesmo tempo que discorre sobre alguns pontos de divergência entre ambos e entre a teoria freudiana. Maroni considera tanto Jung como Nietzsche críticos da modernidade, observando que, na sociedade de massas vivemos, o individualismo democrático, todos os indivíduos se veem como iguais contra uma totalidade. Para a autora, esses dois pensadores propõem uma mudança nos atores desse jogo de forças, defendendo que o embate do indivíduo deveria ser consigo mesmo, que a meta, o compromisso existencial de cada um deveria ser travado com os aspectos negativos e desprezados pelo ego que cada qual traz em si -o que, dentro dos conceitos da Psicologia Analítica é chamado de sombra - e não com uma totalidade, a meu ver muitas vezes abstrata.

Nesse embate consigo próprio, proposto por Jung e Nietzsche para romper com a ordem vigente, ocorre a integração dos aspectos sombrios e o desenvolvimento do processo de individuação processo esse tão caro à Psicologia Analítica -, em que realizaríamos o que temos de mais íntimo e único, aquilo que carregamos em estado germinal desde o início da vida, aquilo que realmente somos valores propostos pela educação coletiva consciente podem vir a ser rompidos, conhecimentos estabelecidos questionados, mas antes o individuo deve ter ao menos se apropriado de tais valores, ter sido inserido na cultura já estabelecida para então vir a questioná-la de forma verdadeiramente consciente. Devemos ressaltar que Jung reconhecia a importância da cultura, que para ele "é a consciência no grau mais alto possível" (1928/2011a, p. 61) e, assim, seu receio relacionava-se não à cultura em si, mas ao risco de supressão da personalidade individual, da negação de si mesmo em prol de certa homogeneização que a própria vida em sociedade em algum grau gera.

Outro elemento interessante que justifica as ressalvas de Jung à educação coletiva é sua própria passagem pela escola. Sua visão a respeito da educação é muito influenciada pela sua experiência nos anos de colégio. Ele chega a propor que a matemática superior seja facultativa nos colégios, pois nem todos teriam a capacidade de compreendêla, sendo demasiadamente abstrata quando ultrapassa o campo dos números concretos (JUNG, 1928/2011a). Tal colocação só pode ser um reflexo da dificuldade nesta área de conhecimento que o próprio autor enfrentou em sua passagem pelo ginásio na Basiléia. Jung ilustra algumas de suas concepções sobre a temática com relatos autobiográficos, como o apresentado na conferência "O bem-dotado" (1943/2011a), em que o autor narra um episódio em que, mesmo tendo se dedicado com esmero a uma redação para a aula de Alemão - com a certeza, a meu ver um tanto arrogante, de que seu trabalho havia sido o melhor, ou pelo menos um dos melhores entre aqueles de sua turma -, não recebeu de seu professor o reconhecimento de seus esforços 
nem seu mérito na tarefa realizada e, como consequência, o autor confessa que nunca mais nada fez para essa disciplina. Esse relato é abordado para alertar educadores sobre o risco que é preterir o "bem-dotado", já que muitas vezes o simples fato de haver uma criança que se destaca pode ser interpretado como perigoso para a ordem vigente.

Temos que comentar que os infortúnios sofridos por Jung em sua escolarização, ainda que sejam elementos pertinentes para se refletir sobre a prática educacional, não podem vir a desqualificar toda uma modalidade de educação, o que acreditamos que o próprio Jung não concordaria, já que ele chega a colocar a educação coletiva como indispensável para sociedade (1928/2011a).

Jung (1928/2011a), ao discorrer sobre o surgimento da consciência, observa que a criança inicialmente tem apenas fragmentos de consciência, comparando-os com ilhas imersas no mar do inconsciente coletivo. Com o tempo essas ilhas se agrupam, formando um continente chamado ego, desenvolvendo a consciência e a noção de eu. Esse primeiro momento da infância, em que a criança ainda não tem o ego suficientemente formado, é fortemente marcado pela participação mística da criança com seus pais. A criança reage à psique de seus pais de forma inconsciente, como se compartilhassem a mesma atmosfera psíquica. Dentro deste contexto, Jung vê a escola como uma instituição que auxilia no processo de formação da consciência, ao "conduzir a criança para o mundo mais amplo e desta forma complementar a educação dada pelos pais" (1928/2011a, p. 65). A escola acaba por se constituir o primeiro ambiente que a criança encontra fora da família, ou seja, o primeiro lugar em que pode percorrer sem seus pais, irmãos e familiares, em que encontra outras referências e identificações, auxiliando no processo de ruptura da participação mística e formação de uma consciência singular. $\mathrm{O}$ autor chega a chamar atenção para o perigo de uma ligação exagerada com a família, o que impediria o adolescente de se integrar ao mundo adulto por manter-se vinculado à psique paterna.

Também a iniciação se constitui como uma experiência decisiva na vida de todos os indivíduos que pertencem às sociedades pré-modernas: ela é uma experiência existencial fundamental, pois é graças a ela que o homem se torna capaz de assumir plenamente seu modo de ser. [...] A cerimônia envolve toda a tribo. Ao instruir uma nova geração, tornando-a digna de ser integrada na comunidade dos adultos; $e$, nessa ocasião, pela reatualização dos ritos tradicionais, toda a comunidade se regenera (Eliade, 1992, p. 27, tradução nossa).

Saviani (2003) concorda com a importância da escola na formação da consciência e articula essa instituição com a noção de ritos de iniciação trazida por Eliade (1992), colocando que nas sociedades modernas, em que esse tipo de rito vem desaparecendo, a escola acaba ocupando seu lugar no que se refere a facilitar o afrouxamento do vínculo do jovem com sua família e inseri-lo na sociedade. $\mathrm{O}$ autor acrescenta ainda que é neste período em que a criança passa na escola que ela gradativamente descobre que o mundo vai além de seu contexto familiar e, consequentemente, começa a desenvolver uma determinada postura de ser e estar em cada contexto social. Lima Filho (2010) coloca que uma das funções da escola é conduzir o aluno do universo familiar ao universo cultural ao qual ele pertence. Dessa forma, a escola também auxilia na construção da persona, que nos termos da Psicologia Analítica é a máscara social necessária, que faz a comunicação entre o que a sociedade requer de nós e a nossa individualidade (FREITAS; LIMA FILHO, 2010).

\section{A educação em nossos tempos: diálogos possíveis}

Atualmente, é muito comum a difusão de projetos pedagógicos fundados na metodologia da educação por competências, inspirados no relatório da Organização das Nações Unidas para Educação, Ciência e Cultura (UNESCO) Educação um tesouro a descobrir (2001), em que a agência da ONU propõe que a educação mundial se dedique a desenvolver o que o relatório denomina de os quatro pilares da educação, que nada mais seriam do que quatro grandes categorias de competências: sociais, relacionais, pessoais e procedimentais. No âmbito nacional, temos, dentre outros documentos, a resolução n. ${ }^{\circ} 3$ de 26 de junho de 1998, do Conselho Nacional de Educação, que estabelece as Diretrizes Curriculares Nacionais para o Ensino Médio, em que institui o desenvolvimento de competências básicas como objetivo fundamental da escolarização.

Não apenas os objetivos do desenvolvimento de competências na educação formal, desprezando o conteúdo curricular em favor do suposto desenvolvimento de habilidades são 
altamente questionáveis, levando para a educação formal um caráter preparatório para o mercado de trabalho, como também a própria possibilidade de que isso ocorra. Será que de fato é possível desenvolver habilidades gerais que possam ser aplicadas independentemente do objeto? Acreditamos que não. Tomemos como exemplo a colocação de Carvalho (2001) sobre a competência do "pensamento crítico", tão desejada por muitos educadores em nossa época.

O pensamento crítico vai muito além de um método de análise que possa ser aplicado a qualquer situação. Ele resulta, dentre outras coisas, de uma formação sólida na área em que se busca realizar uma reflexão. Não que essa formação por si só garanta o pensamento crítico. Porém, se com essa formação sólida em uma área específica o desenvolvimento do pensamento crítico é árduo, sem essa formação ele é impossível. Carvalho (2001) concorda com o exposto ao colocar que:

Assim, embora seja possivel acumular conhecimento sem desenvolver a capacidade crítica, não é possível desenvolver a capacidade crítica sem possuir conhecimentos e informações. Parodiando Kant, "conteúdo sem critica é cego, mas a critica sem conteúdo é vazia" e tende a degenerar em mera contestação barata (CARVALHO, 2001, p. 160).

Arendt já apontava essa incoerência ao criticar o pragmatismo na educação e a opção de desenvolver habilidades independentes dos conhecimentos curriculares tradicionais. Retomando as categorias de educação propostas por Jung, buscamos explicitar a realidade da educação atual e as consequências danosas de aceitar de forma não refletida alguns jargões educacionais contrários à educação coletiva sistematizada, tida como tradicional, reproduzindo a dissociação entre sujeito e objeto, entre forma e conteúdo. Não queremos dar a entender que o que Jung (1928/2011a) defende como educação individual seja o método de educação por competências, de forma alguma nos parece que haja qualquer equivalência entre os dois.

Outro tema rotineiro no âmbito educacional é o do entendimento de que a meta da educação é construir um futuro melhor, ou que as crianças sejam educadas para mudar a sociedade.

A mudança do mundo ${ }^{3}$ é uma tarefa dos adultos em meio à esfera pública por meio da ação e da política, não a partidária, mas sim aquela caracterizada pelo diálogo, argumentação e convencimento entre iguais, portanto, não deveria ser delegada aos mais novos. Assim, educar para a mudança da estrutura social, ou como alguns colocam, educar para "mudar o mundo" seria na verdade tirar das mãos dos mais novos o direito de expressarem sua singularidade e inovarem no futuro, repassando para as novas gerações a tarefa de construir daqui a dez ou vinte anos o mundo que os adultos de hoje consideram o desejado (ARENDT, 2009). Aqui, concordamos com Carvalho (1996) em sua posição nesta questão:

Assim, preparar o futuro pelas mãos de nossos alunos, seja qual for o futuro vislumbrado: uma sociedade sem classes, uma utopia tecnológica pós-moderna ou outra qualquer, significa transferir para eles responsabilidades que são nossas $e$ retirar a responsabilidade, que lhes é própria, pelos caminhos do mundo de amanhã. E simultaneamente significa também que não assumimos nossas responsabilidades, posto que, gostemos ou não deste mundo ao qual pertencemos, por ele somos coletivamente e historicamente responsáveis (CARVALHO, 1996, p. 37).

O ideal pedagógico de educar para a mudança normalmente relaciona-se ao que Jung (1934/2011a) denominou "Educar para a Personalidade", que seria a meta de formar pessoas dotadas de liderança, que estariam à frente das massas em feitos libertadores. $\mathrm{O}$ autor, a meu ver em consonância com Arendt (2009), critica tal ideal pedagógico, comum em seu tempo, e que perdura até nossos dias.

Seria melhor não aplicar às crianças o elevado ideal de educar para a personalidade. A razão disso é que geralmente se vê na "personalidade" a totalidade psíquica, dotada de decisão, resistência e força, mas isso é um ideal de pessoa adulta, que se pretende atribuir à infância. Tal pretensão apenas pode acorrer em uma época em que o indivíduo ainda está inconsciente da sua condição de adulto ou - o que é pior - procura conscientemente esquivar-se dele. Eu tenho minhas dúvidas quanto a real sinceridade desse entusiasmo pedagógico e psicológico. 
(JUNG, 2011a, p. 180).

Jung (1934/ 2011a) antecipa o que anos mais tarde Arendt (2009) coloca como um dos pressupostos básicos que sustentaria a crise vivida na educação norte-americana em meados século XX - não sendo essa crise um fenômeno local, e sim, disseminado no mundo moderno, assumindo formas de expressão diversas em cada país -, que é a concepção de que há uma sociedade composta por crianças, um mundo das crianças, e que se deve na medida do possível deixar que elas se governem. A autora vai ao encontro do argumento de Jung, colocando que se para um adulto já é difícil mostrase contrário às ideias do grupo, para uma criança, que não tem sua personalidade suficientemente formada, isso seria impossível. Assim, a criança em nome de uma suposta valorização da infância ou democracia do Ensino Fundamental, acaba sendo colocada no papel que cabe aos adultos.

Além da falácia dos objetivos, temos que pensar se essa educação para "mudar o mundo" é de fato possível em termos estruturais. Brookover (1977) insere a educação norte-americana dentro de um conjunto de interesses dados pela classe média urbana, industrial e protestante e questiona a possibilidade de que a educação altere a estrutura social, uma vez que esta também se encontra inserida na mesma estrutura. Como seria possível instaurar uma educação libertadora, se o professor não foi liberto? Essa é também a dúvida de Jung (1934/2011a), quando observa que educar para a formação da personalidade só seria viável, dentre outros requisitos, se o próprio professor já fosse uma personalidade. A educação só poderia funcionar como uma agência de mudança dentro da própria estrutura social, assim, seriam necessários outros vetores, além da educação, que atuassem ativamente nesse processo de transformação (BROOKOVER, 1977). Consideramos que essas outras forças capazes de alterar a ordem dada deva ser a ação de adultos em meio à esfera pública.

Conforme dissemos anteriormente, consideramos que uma transformação social efetiva deva ocorrer nessa esfera, efetuada por adultos e não dentro da escola, em uma suposta educação para personalidade ou para transformar o mundo (ARENDT, 2009; JUNG, 1934/2011a). Carvalho (1996), em consonância com o pensamento de Arendt, coloca que "à escola cabe o papel de conservação do mundo cultural e científico construído pelos homens em sua atividade pública" (p.37); assim, a escola teria um compromisso com o mundo público, de apresentar às crianças o que de mais belo foi produzido pela cultura, para que esses conhecimentos não pereçam ao tempo. Além disso, essa é a instituição responsável por levar a criança tanto no âmbito psíquico como social da esfera do lar para um maior e público. Trata-se de um espaço protegido e regido por relações assimétricas, baseadas na autoridade, infelizmente, às vezes no autoritarismo, não podendo ser equiparado à esfera pública, em que a persuasão e o convencimento se dão em relações simétricas entre os homens.

Se encontramos muitas semelhanças entre o pensamento de Jung e Arendt acerca da educação, também podemos traçar algumas divergências claras, tais como o fato de que a educação para Arendt (2009) teria um fim, já que ela se constitui como um processo de aquisição de valores e conceitos compartilhados, em que a criança é introduzida num mundo comum como um todo para que possa vir ao final do processo educacional atuar na esfera pública - diferentemente da aprendizagem, que poderia ocorrer pela vida inteira. Tal concepção é contrária às colocações de Jung (1928/2011a), que defende que a educação de si mesmo é um processo de desenvolvimento afetivo e psicológico que ocorreria ao longo da vida, fazendo apenas a ressalva de que os métodos e fins para educar adultos e crianças são distintos, "o método educacional apropriado ao adulto não pode ser o direto, mas apenas o indireto, que consiste em fornecer-lhe os conhecimentos psicológicos que lhe possibilitem educar-se a si próprio" (JUNG, 1928/2011a, p. 67).

Assim, temos que Jung, ao tratar da educação de adultos, relaciona sua concepção de educação ao próprio processo de individuação, enquanto Arendt relaciona sua concepção de educação à função da Escola. Portanto, dentro das concepções da autora, é coerente considerar que a educação, enquanto processo que visa introduzir a criança no solo comum das tradições e da esfera pública, precisa ter um fim previsível, e, consequentemente, não é possível educar adultos, embora se possa ensiná-los a vida inteira. No presente trabalho, nos ativemos às colocações específicas de Jung sobre a educação de crianças e jovens, não tivemos como foco suas colocações sobre a educação de adultos.

Buscamos explicitar, sobretudo, os prejuízos de aceitar de forma não refletida os jargões educacionais vigentes em nossa época, 
através do resgate das ideias desses dois pensadores, Hannah Arendt e Carl G. Jung sobre a temática da educação formal.

\section{Notas}

$1 \mathrm{O}$ presente artigo refere-se a uma parte da discussão teórica da dissertação de mestrado intitulada "O arquétipo do Mestre-Aprendiz: um estudo sobre os significados da docência sob o enfoque da Psicologia Analítica, pesquisa em andamento, realizada com apoio do $\mathrm{CNPq}$, sob orientação da Prof. Dr ${ }^{\mathrm{a}}$. Laura Villares de Freitas.

2 READ, H. A educação pela arte. Lisboa: Edições 70, 1982.

3 Aqui utilizamos novamente o termo mundo tal qual é conceituado por Hannah Arendt em $A$ Condição Humana (1958/2003) e já esclarecido anteriormente neste artigo.

\section{Referências}

ARENDT, H. A condição Humana. $10^{\mathrm{a}}$ Ed. Rio de Janeiro: Forense Universitária, 2003.

Eichmann em Jerusalém: Um relato sobre a banalidade do mal. São Paulo: Companhia das Letras, 1999.

A crise na Educação. In: ARENDT, $\mathrm{H}$. Entre o passado e o futuro. $6^{\mathrm{a}}$ Ed. São Paulo: Perspectiva, 2009.p. 221- 247.

BRASIL. LDB: Lei de Diretrizes e Bases da Educação Nacional: lei $\mathrm{n}^{\circ}$ 9.394, de 20 de dezembro de 1996, que estabelece as diretrizes e bases da educação nacional. 5. ed. Brasília : Câmara dos Deputados, Coordenação Edições Câmara, 2010. Disponível em:

<http://bd.camara.gov.br/bd/bitstream/handle/bdca mara/2762/ldb_5ed.pdf $>$. Acesso em: 17 ago. 2012.

BRASIL. Resolução CEB No 3, de 26 de junho de 1998, que institui as Diretrizes Curriculares Nacionais para o Ensino Médio. Disponível em: <http://portal.mec.gov.br/cne/arquivos/pdf/rceb03_9 8.pdf $>$. Acesso em 27 jan.2013.

BROOKOVER, W. B. A educação como processo de controle social: função conservadora e função inovadora. In: PEREIRA, L.; FORACCHI, M. M.
(Org.). Educação e Sociedade. São Paulo: Companhia Editora Nacional, 1977. p. 80-87.

CARVALHO, J. S. F. Algumas reflexões sobre o papel da escola de $2^{\circ}$ grau. Revista Paulista de Educação Física. São Paulo, supl. 2, p. 36-39, 1996.

CARVALHO, J. F. S. O discurso pedagógico das diretrizes curriculares nacionais: Competência critica e interdisciplinaridade. Cadernos de Pesquisa. São Paulo, n. 112, p. 155-165, 2001.

ELIADE, M. Initiation, rites, sociétés secrètes. Paris: Idées/Gallimard, 1959.

FREITAS, L. V. Grupos Vivenciais sob uma Perspectiva Junguiana. Psicologia USP, São Paulo, v. 16, n. 3, p. 45-70, 2005.

FREITAS, L. V.; LIMA FILHO, A. P. Pensadores e a Educação: Carl G. Jung. São Paulo: ATTA mídia e educação, 2010. 1 DVD (37 min). ; son. col.

FURLANETTO, E. C. Matrizes Pedagógicas e Formação Docente. In: Congresso Internacional Galego-Português de Psicopedagogia, 10., 2009, Braga. Atas do $\mathbf{X}$ Congresso Internacional Galego-Português de Psicopedagogia. Braga: Universidade do Minho, 2009. Disponível em http://www.educacion.udc.es/grupos/gipdae/congres o/Xcongreso/pdfs/t3/t3c78.pdf $>$ Acesso em 22 jul. 2012.

JUNG, C. G. O desenvolvimento da personalidade. v. XVII. Petrópolis: Vozes, 2011a.

. Os arquétipos e o inconsciente coletivo. v. IX/1. Petrópolis: Vozes, 2011b.

JUNG, C. G.; WILHEKM, R. O segredo da flor de ouro: Um livro da vida chinês. Petrópolis: Vozes, 1984.

MARONI, A. Jung: o poeta da alma. São Paulo: Summus, 1998.

NEUMANN, E. História da origem da consciência. São Paulo: Cultrix, 1995.

SAIANI, C. Jung e a Educação: Uma análise da relação professor/aluno. São Paulo: Escrituras, 2003. 
SILVEIRA, N. Jung: vida e obra. Rio de Janeiro: Paz e Terra, 1981.
UNESCO. Educação: Um tesouro a descobrir. São Paulo: Editora Cortez; Brasília, DF: MEC: UNESCO, 2001.

\section{Sobre a autora:}

Renata Fernandez Targino: Psicóloga e Licenciada, formada pela Universidade de São Paulo (USP), com intercâmbio na Universidade de Lisboa, Portugal. Mestranda em Psicologia Escolar e do Desenvolvimento Humano pela USP. Trabalhou com educação formal e não-formal em escolas privadas e projetos sócioeducativos. 